\title{
Indoor smoking bans in Bulgaria, Croatia, Northern Cyprus, Romania and Turkey
}

\author{
J L Muilenburg, ${ }^{1}$ J S Legge $\mathrm{Jr}^{2}$ A Burdell ${ }^{1}$
}

${ }^{1}$ College of Public Health, University of Georgia, Athens, Georgia, USA

${ }^{2}$ School of Public and International Affairs, University of Georgia, Athens, Georgia, USA

\section{Correspondence to} Jerome S Legge Jr, School of Public and International Affairs, University of Georgia, 206 Candler Hall, Athens, GA 30602. USA; jlegge@uga.edu

Received 27 January 2009 Accepted 20 January 2010 Published Online First 30 July 2010

\section{UNLCKI:D}

This paper is freely available online under the BMJ Journals unlocked scheme, see http:// tobaccocontrol.bmi.com/site/ about/unlocked.xhtml

\author{
ABSTRACT \\ Background The purpose of this study was to examine \\ attitudes towards attempts to limit second-hand smoke \\ (SHS) in five Eastern European nations.
}

Methods The data consist of a Eurobarometer (64.3) survey distributed from November to December 2005. Logistic regression was employed to investigate support levels for indoor smoking bans across the five political units.

Results Across nations, there is more support for smoking bans in offices and indoor work spaces and indoor public space as opposed to restaurants and bars and pubs. Personal smoking behaviours are linked strongly with the smoking bans. Most importantly, it is specific knowledge about the health dangers of smoking which fosters support for indoor smoking bans.

Conclusion Policy implications suggest that government and the media must disseminate accurate information about the harm of smoking to broader segments of the population to gain support for policies that affect the dangers of SHS in these nations.

Eastern European nations have higher smoking rates than their Western European neighbours; similarly, countries in the East lag behind the West in implementing smoking bans. ${ }^{1-5}$ The purpose of this brief report is to assess support for bans on indoor smoking in five nations with high levels of tobacco use and comparatively few restrictions on limiting second-hand smoke (SHS). These nations are Bulgaria, Croatia, Romania, Turkey and the Turkish Republic of Northern Cyprus.

In Bulgaria, Croatia, Romania and Turkey, there are complete smoking bans in healthcare, education and government facilities. Theatres and cinemas also ban smoking in these nations. The most permissive smoking facilities include pubs and bars. There are no restrictions in Romania and Turkey while Bulgaria and Croatia have partial restrictions. After 6 months of experimentation, Croatia partially eased their smoking ban in cafes in response to complaints from smokers and business owners. There are complete bans in indoor workplaces and offices in Bulgaria and Croatia, but only a partial restriction in Turkey and virtually no restrictions in Romania. ${ }^{2}$ Despite these legal restrictions, compliance and enforcement have oftentimes been lax. ${ }^{6}$

\section{METHODS}

The data consist of a Eurobarometer (64.3) survey distributed in November to December 2005.7 In each nation, the sample design consisted of a multistage random probability sample. ${ }^{7}$ The survey research teams carried out a comparison between the sample and the universe in each nation. The universe description was based on Eurostat population data or was drawn from national statistical offices. For all countries, the survey team used a national weighting procedure, using marginal and intercellular weighting, based on the universe description. The iteration procedure took into account gender, age and size of locality. We used the STATA V.10 subprogram SVY: Logistic (regression) to adjust for the complexities of the sampling design. This allowed the application of sample weights for each nation. While the findings are similar when the weights were not utilised, the weighting procedure resulted generally in more conservative estimates and probability levels for the sample size. Further details on the universe sizes can be obtained. ${ }^{6}$ The response rates are as follows: Bulgaria (76.2\%), Croatia (49.3\%), Romania $(91.2 \%)$, Turkey $(68.7 \%)$ and Northern Cyprus $(89.8 \%)$. For the dependent variables, respondents were asked to express their support for bans on smoking in one of four locations: restaurants; bars or pubs; offices and other indoor workspaces; and any indoor public space such as metros, airports and shops. The specific question is, "Are you in favour of smoking bans in the following places?"

The dependent variable originally consisted of five categories (totally opposed to totally in favour); however, an initial ordered logit analysis did not meet the assumption of parallel regressions as indicated by Brant tests in all equations. Thus, we used a logistic regression analysis where $1=$ totally in favour or somewhat in favour, and $0=$ totally opposed, somewhat opposed or don't know.

For the explanatory variables, we first measured country-specific effects with dummy variables that were created for Bulgaria, Croatia, Northern Cyprus and Turkey $(1,0)$. Romania serves as the reference (comparison) nation. Two binary variables were created for ex-smokers and non-smokers. The reference category is current smokers. Five possible responses (never to often) were utilised to measure how often an individual was bothered by exposure to tobacco smoke in their daily lives. Assertiveness on SHS was measured by a fivecategory question (also never to often) that queried whether the respondent ever asked a smoker not to smoke because it bothered him/her. Ideology was captured in a 10-point question where high values represented the right and low values represented the left. Government role legitimacy in health was tapped by a five-category question (totally disagree to totally agree) that asked whether government should "encourage people to eat a healthy diet and take plenty of exercise". A satisfactory diet 
Table 1 Support for indoor smoking bans in Romania, Bulgaria, Northern Cyprus and Croatia and Turkey

\begin{tabular}{llllll}
\hline Nation & \multicolumn{1}{l}{ Romania } & Bulgaria & N Cyprus & Croatia & Turkey \\
\hline \multicolumn{2}{l}{ Per cent "Totally in favor" or "Somewhat in favor" } & & & & \\
Smoking in restaurants & $58.6 \%$ & $64.7 \%$ & $79.12 \%$ & $67.6 \%$ & $81.3 \%$ \\
Smoking in bars and pubs & $50.59 \%$ & $59.2 \%$ & $73.0 \%$ & $46.1 \%$ & $70.8 \%$ \\
Smoking in indoor work places & $69.0 \%$ & $83.3 \%$ & $82.8 \%$ & $82.0 \%$ & $85.6 \%$ \\
Smoking in indoor public spaces* & $72.0 \%$ & $84.7 \%$ & $83.4 \%$ & $82.1 \%$ & $85.8 \%$ \\
$\mathrm{n}$ & 1002 & 1004 & 500 & 1000 & 1005 \\
\hline$*$
\end{tabular}

*Indoor public spaces include metros, airports and shops.

consisted of five categories (no, not good at all to yes, very good) in answer to the statement "what I eat is good for my health". General health was measured by five categories (very bad to very good). We utilised a five-point question (totally disagree to totally agree) to assess whether the respondent believed that smoking "in the presence of a pregnant woman can be dangerous to the baby". We used a binary variable to determine if the respondent believed that SHS is "harmless" or "harmful". The researchers constructed binary variables for gender, manual worker and unemployment. Women, manual workers and the unemployed were coded " 1 " with the remainder of the sample coded as "0". We measured education by the total years spent in school.

\section{RESULTS}

Table 1 lists the percentages of those "totally in favor" or "somewhat in favor" of the smoking bans. Across nations, the greatest level of support for the antismoking measures is found concerning smoking in indoor workplaces and indoor public spaces. There is much less support for smoking bans in restaurants and bars and pubs. Overall, Romania demonstrates the least support for indoor smoking bans except for smoking bans in bars and pubs, where the Croatians are less likely to be supportive.

Table 2 shows the results of the four multivariable logistic regressions. There is evidence of a strong, consistent nationspecific effect, consistent with the results in table 1 . Nonsmokers and ex-smokers are more amenable than current smokers towards indoor smoking bans, with higher odds ratios for restaurants and bars and pubs.

On three of the four dependent variables, being bothered by SHS was associated with increased support for smoking bans. More important is individual assertiveness concerning SHS; if a respondent would ask a smoker not to smoke, the ORs are from 1.27 to 1.34 times greater that they would support indoor smoking bans of all types.

Table 2 Logistic regression explaining attitudes towards indoor smoking bans (ORs)

\begin{tabular}{|c|c|c|c|c|c|c|c|c|c|c|c|c|}
\hline \multirow[b]{2}{*}{ Explanatory variables } & \multicolumn{3}{|c|}{ Restaurants } & \multicolumn{3}{|c|}{ Bars and pubs } & \multicolumn{3}{|c|}{ Offices } & \multicolumn{3}{|c|}{ Indoor spaces } \\
\hline & $\overline{\mathbf{O R}}$ & $95 \% \mathrm{CI}$ & $\mathbf{p}$ & $\overline{\mathbf{O R}}$ & $95 \% \mathrm{Cl}$ & $\mathbf{p}$ & $\overline{O R}$ & $95 \% \mathrm{CI}$ & $\mathbf{p}$ & $\overline{\text { OR }}$ & $95 \% \mathrm{CI}$ & $\mathbf{p}$ \\
\hline \multicolumn{13}{|l|}{ Nation dummies } \\
\hline Bulgaria & 1.66 & 1.35 to 2.03 & $<0.001$ & 1.86 & 1.52 to 2.28 & $<0.001$ & 2.72 & 2.15 to 3.46 & $<0.001$ & 2.50 & 1.96 to 3.19 & $<0.001$ \\
\hline Croatia & 2.07 & 1.66 to 2.58 & $<0.001$ & 998 & 0.814 to 1.22 & 0.987 & 2.64 & 2.08 to 3.37 & $<0.001$ & 2.20 & 1.73 to 2.80 & $<0.001$ \\
\hline Turkey & 3.09 & 2.39 to 3.99 & $<0.001$ & 2.32 & 1.83 to 2.96 & $<0.001$ & 2.26 & 1.72 to 2.97 & $<0.001$ & 1.97 & 1.50 to 2.59 & $<0.001$ \\
\hline \multicolumn{12}{|l|}{ Smoking behaviour } & $<0.001$ \\
\hline Ex-smoker & 2.43 & 1.90 to 3.11 & $<0.001$ & 2.08 & 1.66 to 2.60 & $<0.001$ & 2.08 & 1.53 to 2.82 & $<0.001$ & 1.97 & 1.43 to 2.71 & $<0.001$ \\
\hline Non-smoker & 2.47 & 2.08 to 2.93 & $<0.001$ & 2.77 & 2.34 to 3.27 & $<0.001$ & 1.44 & 1.18 to 1.75 & $<0.001$ & 1.24 & 1.02 to 1.51 & 0.032 \\
\hline Bothered by SHS & 1.12 & 1.07 to 1.18 & $<0.001$ & 1.07 & 1.02 to 1.12 & $<0.008$ & 1.09 & 1.03 to 1.15 & 0.003 & 1.03 & 0.973 to 1.09 & 0.330 \\
\hline $\begin{array}{r}\text { Assertiveness on SHS } \\
\text { Role of government }\end{array}$ & 1.34 & 1.26 to 1.43 & $<0.001$ & 1.27 & 1.20 to 1.34 & $<0.001$ & 1.27 & 1.18 to 1.37 & $<0.001$ & 1.28 & 1.19 to 1.38 & $<0.001$ \\
\hline Ideology & 983 & 0.951 to 1.02 & 0.338 & 996 & 0.963 to 1.03 & 0.799 & 963 & 0.928 to 0.999 & 0.045 & 964 & 0.927 to 1.10 & 0.058 \\
\hline $\begin{array}{l}\text { Government role legitimate } \\
\text { Health }\end{array}$ & 1.13 & 1.06 to 1.20 & $<0.001$ & 1.14 & 1.07 to 1.20 & $<0.001$ & 1.11 & 1.04 to 1.19 & 0.001 & 1.07 & 0.998 to 1.14 & 0.055 \\
\hline Diet & 1.01 & 0.929 to 1.09 & 0.854 & 1.06 & 0.982 to 1.14 & 0.135 & 980 & 0.896 to 1.07 & 0.671 & 1.03 & 0.939 to 1.13 & 0.544 \\
\hline \multicolumn{12}{|l|}{ Smoking belief knowledge } & 0.067 \\
\hline Hurt pregnant women & 1.33 & 1.22 to 1.45 & $<0.001$ & 1.22 & 1.12 to 1.33 & $<0.001$ & 1.43 & 1.32 to 1.56 & $<0.001$ & 1.41 & 1.29 to 1.53 & $<0.001$ \\
\hline \multicolumn{12}{|l|}{ Demographics } & 0.014 \\
\hline Gender & 0.961 & 0.824 to 1.12 & 0.612 & 1.00 & 0.869 to 1.16 & 0.953 & 1.06 & 0.894 to 1.26 & 0.493 & 1.02 & 0.859 to 1.21 & 0.818 \\
\hline Age & 1.01 & 1.00 to 1.01 & 0.004 & 1.01 & 1.01 to 1.02 & 0.001 & 1.00 & 0.997 to 1.01 & 0.214 & 1.00 & 0.997 to 1.01 & 0.286 \\
\hline Manual worker & 1.00 & 0.821 to 1.23 & 0.974 & 1.10 & 0.913 to 1.34 & 0.304 & 1.06 & 0.842 to 1.33 & 0.623 & 1.10 & 0.869 to 1.39 & 0.432 \\
\hline Unemployed & 1.00 & 0.773 to 1.30 & 0.978 & 1.02 & 0.787 to 1.32 & 0.894 & 1.05 & 0.790 to 1.41 & 0.713 & 1.24 & 0.914 to 1.69 & 0.165 \\
\hline $\begin{array}{l}\text { Education } \\
\mathrm{n}=4511\end{array}$ & 1.01 & 0.922 to 1.11 & 0.817 & 0.942 & 0.867 to 1.02 & 0.166 & 0.980 & 0.885 to 1.08 & 0.702 & 0.984 & 0.889 to 1.09 & 0.762 \\
\hline \multicolumn{4}{|l|}{$\mathrm{df}=19$} & \multicolumn{3}{|c|}{$34.4(p<0.001)$} & \multicolumn{3}{|c|}{$18.08(p<0.001)$} & & & \\
\hline$\%$ Cases correctly classified & $73.9 \%$ & & & $69.5 \%$ & & & $80.2 \%$ & & & $81.2 \%$ & & \\
\hline
\end{tabular}


Ideology was significant only in the case of smoking in offices with those on the right somewhat less likely to support the ban. Those who view government as having a strong role in health are more likely to support the smoking bans across all categories, except for the marginal 0.055 level of significance for indoor spaces. Higher general health was associated with greater support for smoking bans in restaurants and offices.

Knowledge of the general harmful effects of smoking and the negative effects of SHS on pregnancies is strongly and consistently related to increased support for the indoor bans.

The present analysis demonstrates no strong demographic effects, with one exception-age; the older the individual, the greater the support for bans in restaurants and bars.

\section{DISCUSSION}

The limitations of this study include the fact that the data on smoking behaviour are self-reported. Given that tobacco use is a somewhat sensitive social issue, there may be some imprecision in the responses. In addition, the results can be generalised only to the nations included in this study, which have a history of high tobacco consumption.

Notwithstanding these limitations, the findings have important implications for policy and practice. First, although smoking is a huge public health problem among these nations, there are important differences in support. Romania has the largest problem in attaining acceptance of the bans. With the exception of Croatia in the case of bars and pubs, support for the indoor bans is stronger across every nation and for each dependent variable. Nonetheless, it is important to note that there was major support in each country for bans in restaurants, bars and pubs, indoor workspaces, and indoor public places (the only exception being support for smoke-free bars and pubs among Croatians), and the support was greater than $70 \%$ in 13 of the 20 combinations of locations and country (see table 1). These findings should be advertised to the general population, and to policy makers and other key opinion leaders.

Second, as has been well-documented in the literature, individuals' attitudes are associated with their own smoking behaviour. $^{8} 9$ Smokers are less supportive of bans that limit their behaviour. Those who reported better health in general are more supportive of smoking bans. ${ }^{10}$ Further, younger respondents are less likely to support smoking bans than older respondents. ${ }^{11-16}$

The best potential for increasing support for indoor smoking bans appears to be respondents learning about the harmful

\section{What this paper adds}

- Many studies of tobacco control policies demonstrate that demographic variables are associated with support for such policies. Age, gender, class, education and employment status have been strong predictors of support for antismoking policies and tobacco use in general.

- In this analysis of indoor smoking bans in Bulgaria, Croatia, Northern Cyprus, Romania and Turkey, demographic variables are of little importance. Instead, knowledge of the potentially harmful effects of tobacco emerges as the more important and consistent explanation of support for these policies. Our findings suggest that public health practitioners in these nations should focus on widely disseminating accurate information on the health effects of second-hand smoke. effects of SHS. ${ }^{17-19}$ The analysis has demonstrated that individuals who know about the harmful effects of SHS are more apt to support bans on indoor smoking than others. Media and government must disseminate accurate information on the health effects of SHS if there are to be substantial changes in behaviour. Current efforts include those by the World Health Organization in these nations that encourage utilisation of primary care providers, advocate strong leadership in community and government organizations, and media campaigns to relay information that will increase knowledge and decrease smoking. ${ }^{20}$ This information will continue to compete against strong cultural norms that encourage smoking in these Eastern European nations.

Acknowledgements The authors acknowledge the following sources: Papacostas, Antonis. 2007. Eurobarometer 64:3 Foreign Languages, Biotechnology, Organised Crime, and Health Items, November-December 2005 [Computer File], ICPSR04590v2, Brussels, Belgium: TNS Opinion and Social /EOS Gallup Europe [producers], 2006. Cologne, Germany: Zentralarchiv für Empirische Socialforschung/Ann Arbor, MI: Inter-university Consortium for Political and Social Research [distributors], 2007 04-11. The distributor of the data, the Inter-university Consortium for Political and Social Research, University of Michigan, and the Eurobarometer Survey team bear no responsibility for the analysis and interpretations presented in this article. We also wish to thank Professors Jamie Carson and Ryan Bakker, Department of Political Science, University of Georgia, for their comments on the methodology used in this study.

\section{Competing interests None.}

Ethics approval This study was conducted with the approval of the TNS Opinion and Social/EOS Gallup Europe, Brussels, Belgium.

Contributors JLM wrote the manuscript and edited the content. JSL conducted data analysis and wrote the analysis section of the paper. $A B$ assisted with data analysis and contributed to written sections of the manuscript.

Provenance and peer review Not commissioned; externally peer reviewed.

\section{REFERENCES}

1. Patel T. Eastern Europe heads for smoking catastrophe, 1994. http://www newscientist.com/article/mg14419481.400-eastern-europe-heads-for-smoking.

2. World Health Organization. The European report on tobacco health policy. Geneva: World Health Organization, 2002.

3. Rasmussen SR, Prescott E, Sørensen TI, et al. The total lifetime costs of smoking. Eur J Public Health 2004;15:95-100.

4. Rasmussen SR, Prescott E, Sørensen TI, et al. The total lifetime health cost savings of smoking cessation to society. Eur J Public Health 2005;15:601-6.

5. Erbaydar T, Lawrence S, Dagli E, et al. Influence of social environment in smoking among adolescents in Turkey. Eur J Public Health 2005;15:404-10.

6. Romania Official Travel and Tourist Information. http://www.romaniatourism.com/ info.html.

7. Papacostas A. Foreign Languages, Biotechnology, Organized Crime, and Health Items, November-December 2005 [Computer File], ICPSR04590-v2, Brussels, Belgium: TNS Opinion and Social/EOS Gallup Europe [producers], 2006. Cologne, Germany: Zentralarchiv für Empirische Socialforschung/Ann Arbor, Ml: Interuniversity Consortium for Political and Social Research [distributors], 04-11. For online information on the sample see 2007. Eurobarometer 64.3. http://www.icpsr umich.edu/icpsrweb/ICPSR/studies/4590/documentation.

8. Helasoja V, Prättälä R, Klumbiene J, et al. Smoking and passive smoking in Estonia, Lithuania, and Finland: identifying target groups of tobacco policy. Eur J Public Health 2001;11:206-10.

9. Schumann A, John U, Thyrian JR, et al. Attitudes towards smoking policies and tobacco control measures in relation to smoking status and smoking behaviour. Eur $J$ Public Health 2006;16:13-519.

10. Abel T, McQueen DV. Determinants of selected unhealthy eating behaviors among male and female adults. Eur J Public Health 1994;4:27-32.

11. Boshnakova D. Number of young smokers in Bulgaria up. The Sophia Echo 2007 http://www.sofiaecho.com/article/number-of-young-smokers-in-bulgaria-up/ id 22163/cat.3.

12. Novinite.com. WHO: smoking ups Bulgaria's death rate, 2003. http://www.novinite com/view news.php?id $=28070$.

13. Anatchkova MD, Redding CA, Rossi JS. Factors associated with smoking cessation and risk of smoking initiation in Bulgarian youth. Calif J Health Promotion 2006;4:1-12

14. Brown P. Smoking increases among teenagers in eastern Europe. Brit Med J 2002;324:442.

15. Johansson A, Halling $A$, Hermansson $G$. Indoor and outdoor smoking: impact on children's health. Eur J Public Health 2003;13:61-6.

16. Ertas E. Factors associated with stages of cigarette smoking among Turkish youth Eur J Public Health 2006;17:155-61. 
17. Dokova KG, Stoeva KJ, Kirov Pl, et al. Public understanding of the causes of high stroke risk in northeast Bulgaria. Eur J Public Health 2005;15:313-16.

18. Kurtz ME, Kurtz JC, Contreras D, et al. Knowledge and attitudes of economically disadvantaged women regarding exposure to environmental tobacco smoke. Eur $J$ Public Health 2003:13:171-6.
19. Paavola M, Vartianen E, Haukkala A. Smoking from adolescence to adulthood: the effects of parental and own socioeconomic status. Eur $J$ Public Health 2004;14:417-21.

20. The World Health Organization. WHO European strategy for smoking cessation policy, 2004. http://www.euro.who.int/Document/E80056.pdf. 